\title{
PRODUÇÃO DE CARNE ENTRE CORDEIROS CASTRADOS E NÃO CASTRADOS. 1. CRUZAS HAMPSHIRE DOWN X CORRIEDALE
}

\author{
MEAT PRODUCTION BETWEEN CASTREDED AND NON-CASTREDED \\ LAMBS. 1. CROSSBRED HAMPSHIRE DOWN X CORRIEDALE
}

\begin{abstract}
José Carlos da Silveira Osório ${ }^{1}$ Pedro Osório da Conceição Jardim ${ }^{2}$ Marcelo Alves Pimentel ${ }^{2}$ Juvêncio Pouey $^{3}$ Maria Teresa Moreira Osório $^{3}$ Werner Erwin Lüder ${ }^{2}$ Marcos Flávio Borba ${ }^{4}$
\end{abstract}

RESUMO

O estudo comparou a produção de carne entre 13 cordeiros castrados aos 45 dias e 13 não castrados, procedentes do cruzamento de ovelhas Corriedale com Hampshire Down, nascidos em agosto de 1996 e abatidos aos 5 meses de idade, criados em condições extensivas de pastagem natural, na localidade de Aceguá, município de Bagé-RS. Foram coletados dados de produção de carne, morfologia in vivo e, na carcaça, componentes do peso vivo, composição regional e tecidual. Não se verificou diferença significativa entre cordeiros castrados e não castrados, concluindo-se que não há vantagem, quanto à produção de carne, em castrar os cordeiros muito jovens.

Palavras-chave: efeito-castração, carne ovina, carcaça, cordeiro.

\section{SUMMARY}

This study has compared meat production among two groups of crossbred lambs Hampshire Down $x$ Corriedale: 13 castrated at 45 days of age and 13 non-castrated (all born in August 1996 and slaughtered when five months old). The flock was raised on natural pasture, under an extensive grazing system, in Aceguá, Bagé, State of Rio Grande do Sul, Brazil. The characteristics research were meat production, morfology "in vivo" and carcass, living weight components, regional and tissue composition. There is no significant difference between castrate lambs and not castrate lambs. The results showed that there is not advantage in to castrate very young lambs, when the purpose is meat production.

Key words: effect of castration, sheep meat, carcass, lamb.

\section{INTRODUÇÃO}

O engorduramento é o elemento mais importante na fixação do preço e que melhora a qualidade da carcaça (THERIEZ, 1985); sendo a raça, peso de nascimento, sexo e sistema de criação, fatores que influem na obtenção de carcaças de alta qualidade sempre que o estado de maturidade ao abate seja precoce. Por outro lado, dentro da mesma raça e em igual peso de carcaça, SIERRA (1973) observou que as fêmeas apresentam carcaças mais gordas, o que também foi comprovado por EVERITT \& JURY (1966), ANDREWS \& ORSKOV (1970a,b), COLOMER \& ESPEJO (1973), VEZINHET \& PRUD'HON (1975) e TAYLOR et al.(1989).

Neste sentido, FIELD (1971), SEIDMAN et al. (1982) e SAFARI et al.(1988) constataram que os machos inteiros podem reduzir a gordura em carcaças de pesos similares em relação a machos castrados. Também CARPENTER et al.(1969) observaram uma maior percentagem de carne nos machos frente às fêmeas e machos castrados e, por sua vez, as carcaças das fêmeas apresentaram uma maior percentagem de gordura e menor de carne do que a dos machos castrados.

KEMP et al.(1981) observaram que a gordura subcutânea das cordeiras teve uma percen-

\footnotetext{
${ }^{1}$ Médico Veterinário, Mestre, Doutor, Professor Titular, Bolsista do CNPq, Universidade Federal de Pelotas (UFPEL), Faculdade de Agronomia Eliseu Maciel (FAEM), Zootecnia, 96010-900, Pelotas,RS. E-mail: jcosorio@ufpel.tche.br. Autor para correspondência.

${ }^{2}$ Médico Veterinário, Mestre, Professor Adjunto, UFPEL, FAEM, Zootecnia.

${ }^{3}$ Médico Veterinário, Doutor, Professor Adjunto, UFPEL, FAEM, Zootecnia.

${ }^{4}$ Médico Veterinário, Mestre, Pesquisador EMBRAPA-CPPSUL, Bagé-RS.
} 
tagem bem maior de ácido oleico e ácidos graxos insaturados do que a gordura subcutânea de machos castrados. A gordura subcutânea de machos inteiros teve uma maior percentagem de ácido palmitoleico e ácidos graxos insaturados, mas uma menor percentagem de ácido esteárico que a gordura subcutânea dos machos castrados. A gordura intramuscular de cordeiros inteiros teve uma percentagem mais elevada de ácidos palmitoleico e linoleico que a de castrados.

OLIVER et al.(1967) afirmam haver diferenças significativas entre machos e fêmeas quanto à gordura perirenal (maior nas fêmeas), diferença esta que não é observada entre machos inteiros e castrados.

Também, em estudo realizado por LLOYD et al. (1981), verifica-se que o sexo, juntamente com a raça, influencia o rendimento de carcaça; sendo que os cordeiros inteiros apresentam maior rendimento que castrados, embora estes últimos tenham melhor conformação e peso, subjetivamente.

Segundo LLOYD et al. (1981), a palatabilidade da carne de animais castrados e inteiros não difere significativamente. Entretanto, deve-se ressaltar que dentro de uma raça, o efeito de sexo sobre a composição tecidual pode acentuar-se segundo o peso de abate, sendo as fêmeas mais adiposas que os machos (LOPEZ et al., 1991).

O presente estudo objetiva comparar a produção de carne em cordeiros procedentes do cruzamento de ovelhas da raça Corriedale com carneiro Hampshire Down.

\section{MATERIAL E MÉTODOS}

Foram utilizados 26 cordeiros cruzas de ovelhas Corriedale com Hampshire Down, sendo 13 castrados aos 45 dias de idade e 13 não castrados; esses cordeiros nasceram em agosto de 1996 e foram criados em condições extensivas de campo nativo, juntamente com as mães até o abate (5 meses de idade), na localidade do Aceguá, município de BagéRS. O critério de eleição dos cordeiros a serem castrados, foi pela avaliação visual e tátil; ou seja, buscava-se dois cordeiros de similar tamanho, conformação e condição corporal, um era castrado e o outro não.

Aos 5 meses de idade, os cordeiros, após jejum, sem água, de 17 horas, foram pesados individualmente e realizada as seguintes medidas, segundo métodos descritos por OSÓRIO et al. (1990): conformação (índice de $1=$ muito pobre a $5=$ excelente), condição corporal (índice de $1=$ muito pobre a $5=$ excelente), comprimento corporal, comprimento da perna, altura do cordeiro e perímetro toráico.

Imediatamente, os cordeiros foram abatidos (suspendido pela pata e perfurando a jugular com uma faca, deixando escorrer o sangue) e tomando o peso dos componentes do peso vivo (carcaça quente com os rins, vísceras verdes, pele, cabeça, patas, pulmões com traquéia, fígado, coração e baço). A seguir, foram transportadas as carcaças para o laboratório da Universidade Federal de Pelotas e acondicionadas em câmara fria a $1^{\circ} \mathrm{C}$, durante 18 horas, quando tomou-se o peso da carcaça fria, avaliou-se a conformação (índice de 1=má menos a 12=muito boa mais, segundo MÜLLER, 1987) e o estado de engorduramento (OSÓRIO et al., 1990) e, separou-se longitudinalmente, com serra elétrica, a carcaça em duas metades. Na metade esquerda foi tomado o comprimento interno da carcaça, comprimento da perna, profundidade do peito e, imediatamente, seccionado o músculo Longissimus dorsi entre a $12^{\mathrm{a}}$ e $13^{\mathrm{a}}$ costelas e medida a área de olho de lombo, espessura da gordura de cobertura, textura, marmoreio e cor (OSÓRIO et al., 1990). Retirou-se os rins e a gordura renal e pélvica e pesou-se. Na metade direita da carcaça, foi realizada a separação regional (pescoço, paleta, costilhar e perna) e pesados e, na paleta e perna, foi feita a separação dos componentes teciduais (osso, músculo e gordura).

Foram calculadas as seguintes características: rendimento verdadeiro $=$ peso da carcaça quente/peso vivo sacrifício x 100, rendimento comercial $=$ peso da carcaça fria/peso vivo sacrifício $\mathrm{x}$ 100 , compacidade corporal $=$ peso vivo sacrifício/comprimento corporal, compacidade da carcaça = peso da carcaça fria/comprimento interno da carcaça, percentagem dos componentes do "quinto quarto" (vísceras verdes, pele, cabeça, patas, pulmões com traquéia, fígado, rins, coração, baço) em relação ao peso vivo sacrifício, percentagem dos componentes regionais em relação ao peso da carcaça fria, percentagem da composição tecidual da paleta e quarto em relação ao peso da paleta e quarto, respectivamente.

Através da análise de variância dos dados, foi verificado o efeito da castração (castrados x não castrados), seguindo o modelo matemático $\mathrm{Y}$ ij = média + efeito da castração $\mathrm{i}+$ erro experimental j; sendo $\mathrm{Y}$ as características tomadas, $\mathrm{i}=$ castrados $\mathrm{e}$ não castrados e j o erro experimental. Foi utilizado o programa estatístico de computador SAS (1982).

\section{RESULTADOS E DISCUSSÃO}

Verifica-se que, embora estatisticamente não significativo, os animais não castrados apresentaram um peso vivo e de carcaça superior aos cordeiros castrados (Tabela 1); assim como, maior compacidade corporal, de carcaça e de perna. Quanto a maior peso dos cordeiros inteiros, os resultados eram 
esperados, visto que estes apresentam superior velocidade de crescimento em relação aos cordeiros castrados (AZZARINI \& PONZONI, 1971). Entretanto, não são as carcaças dos cordeiros inteiros com maior quantidade de gordu$\mathrm{ra}$; mostrando que, estes reduzem a gordura em relação aos machos castrados (SEIDEMAN et al., 1982 e SAFARI $\boldsymbol{e t}$ al., 1988).

Os cordeiros não castrados não diferiram dos castrados quanto aos componentes do peso vivo, composição regional (salienta-se que os cordeiros não castrados apresentaram tendência para maior proporção de cabeça e pescoço do que os cordeiros castrados) e tecidual da paleta e perna (Tabela 2). Entretanto, o esperado era uma superior quantidade de gordura nos castrados e maior massa muscular nos machos não castrados (CARPENTER $\boldsymbol{e t}$ al., 1969). Cabe ressaltar que não houve diferença entre cordeiros castrados e não castrados em rendimento de carcaça e espessura de gordura de cobertura; porém, os machos inteiros apresentam uma superior área de músculo Longissimus dorsi e maior superioridade de pescoço e músculo na paleta e perna. Resultados que parecem coerentes e esperados.

Do ponto de aplicação prática e com embasamento nos resultados obtidos, não recomendase a realização da castração de cordeiros criados sobre as condições do presente experimento. Comercialmente, as carcaças desses cordeiros devem receber semelhante valorização e, inclusive, fazerem parte da mesma classificação.

\section{CONCLUSÕES}

Não há vantagem em castrar cordeiros na busca do incremento da produção da carne, em cordeiros cruzas de ovelhas Corriedale com carneiros Texel, até os 5 meses de idade.

\section{REFERÊNCIAS BIBLIOGRÁFICAS}

ANDREWS, R.P., ORSKOV, E.R. The nutrition of the early weaned lamb. I. The influence of protein concentration and feeding level on rate of gain in body weight. Journal of Agric. Science, v. 75, p. 11-18, 1970a.

ANDREWS, R.P., ORSKOV, E.R. The nutrition of the early weaned lamb. II. The effect of dietary protein concentration, feeding level and sex on body composition and two live weights. Journal of Agricultural Science, v. 75, p. 19-26, 1970b.

AZZARINI, M., PONZONI, R. Aspectos modernos de la producción ovina. Montevideo, Uruguay: Universidad de la Republica, $1971.75 \mathrm{p}$.
Tabela 1 - Médias e desvios-padrões das características de produção, morfologia e na secção do músculo Longissimus dorsi.

\section{CASTRADOS INTEIROS Prob.>F}

\begin{tabular}{lccc}
\hline Peso vivo jejum $(\mathrm{kg})$ & $27,53 \pm 3,44$ & $30,63 \pm 4,76$ & 0.09 \\
Peso carcaça quente $(\mathrm{kg})$ & $12,05 \pm 1,99$ & $13,35 \pm 2,84$ & 0.19 \\
Peso carcaça fria $(\mathrm{kg})$ & $11,65 \pm 2,01$ & $12,92 \pm 3,10$ & 0.23 \\
Rendimento verdadeiro $(\%)$ & $43,24 \pm 2,53$ & $43,33 \pm 2,45$ & 0.92 \\
Rendimento comercial $(\%)$ & $41,78 \pm 2,69$ & $41,79 \pm 3,19$ & 0.99 \\
Perda resfriamento $(\mathrm{kg})$ & $0,400 \pm 0,374$ & $0,439 \pm 0,310$ & 0.78 \\
Perda resfriamento $(\%)$ & $3,35 \pm 2,81$ & $3,64 \pm 2,14$ & 0.77 \\
Compacidade corpo $(\mathrm{kg} / \mathrm{cm})$ & $0,466 \pm 0,046$ & $0,504 \pm 0,058$ & 0.08 \\
Compacidade carcaça $(\mathrm{kg} / \mathrm{cm})$ & $0,211 \pm 0,027$ & $0,229 \pm 0,041$ & 0.21 \\
Conformação vivo $(1-5)$ & $2,3 \pm 0,4$ & $2,4 \pm 0,7$ & 0.75 \\
Conformação carcaça $(1-12)$ & $6,2 \pm 1,4$ & $6,6 \pm 1,9$ & 0.49 \\
Condição corporal $(1-5)$ & $2,0 \pm 0,5$ & $2,1 \pm 0,8$ & 0.73 \\
Gordura carcaça $(1-5)$ & $2,1 \pm 0,8$ & $2,5 \pm 1,0$ & 0.24 \\
Espessura gordura $(\mathrm{cm})$ & $0,005 \pm 0,007$ & $0,004 \pm 0,008$ & 0.69 \\
Área olho de lombo $(\mathrm{cm})$ & $10,2 \pm 2,6$ & $11,99 \pm 2,59$ & 0.11 \\
Marmoreio $(1-5)$ & $1,7 \pm 0,9$ & $2,1 \pm 1,4$ & 0.40 \\
Cor carne $(1-5)$ & $3,8 \pm 0,4$ & $4,0 \pm 0,4$ & 0.32 \\
Compacidade perna $(\mathrm{kg} / \mathrm{cm})$ & $0,058 \pm 0,009$ & $0,063 \pm 0,011$ & 0.17 \\
Comprimento corporal $(\mathrm{cm})$ & $59,54 \pm 3,84$ & $60,54 \pm 2,57$ & 0.44 \\
Comprimento perna $(\mathrm{cm})$ & $48,42 \pm 6,43$ & $51,08 \pm 2,23$ & 0.19 \\
Altura in vivo $(\mathrm{cm})$ & $58,23 \pm 2,52$ & $58,46 \pm 4,56$ & 0.87 \\
Perímetro toráxico $(\mathrm{cm})$ & $71,31 \pm 3,09$ & $72,69 \pm 4,15$ & 0.34
\end{tabular}

Tabela 2 - Médias e desvios-padrões das características dos componentes do peso vivo, composição regional e composição tecidual da paleta e quarto.

\begin{tabular}{lccc}
\hline & & & \\
& CASTRADOS & INTEIROS & Prob.>F \\
\hline & & & \\
\hline & & & \\
Carcaça quente (\%) & $43,24 \pm 2,53$ & $43,33 \pm 2,45$ & 0.92 \\
Vísceras verdes (\%) & $26,37 \pm 2,27$ & $25,67 \pm 4,10$ & 0.59 \\
Pele (\%) & $13,82 \pm 1,04$ & $13,40 \pm 1,24$ & 0.36 \\
Cabeça (\%) & $4,19 \pm 0,42$ & $4,27 \pm 0,45$ & 0.64 \\
Patas (\%) & $2,32 \pm 0,33$ & $2,30 \pm 0,32$ & 0.85 \\
Pulmões e traquéia (\%) & $1,70 \pm 0,29$ & $1,52 \pm 0,16$ & 0.06 \\
Fígado (\%) & $1,66 \pm 0,30$ & $1,38 \pm 0,11$ & 0.003 \\
Rins (\%) & $0,47 \pm 0,61$ & $0,64 \pm 0,88$ & 0.56 \\
Coração (\%) & $0,47 \pm 0,04$ & $0,46 \pm 0,05$ & 0.52 \\
Baço (\%) & $0,11 \pm 0,02$ & $0,10 \pm 0,03$ & 0.30 \\
Pescoço (kg) & $0,463 \pm 0,094$ & $0,674 \pm 0,535$ & 0.17 \\
Pescoço (\%) & $8,30 \pm 0,95$ & $10,70 \pm 7,60$ & 0.27 \\
Paleta (kg) & $1,122 \pm 0,147$ & $1,239 \pm 0,214$ & 0.12 \\
Paleta (\%) & $20,24 \pm 1,12$ & $20,23 \pm 1,08$ & 0.98 \\
Costilhar (kg) & $1,948 \pm 0,436$ & $1,989 \pm 0,772$ & 0.87 \\
Costilhar (\%) & $34,73 \pm 2,43$ & $31,99 \pm 7,61$ & 0.23 \\
Perna (kg) & $2,048 \pm 0,361$ & $2,282 \pm 0,474$ & 0.17 \\
Perna (\%) & $36,73 \pm 1,73$ & $37,08 \pm 1,61$ & 0.60 \\
Osso paleta (\%) & $24,04 \pm 1,64$ & $23,52 \pm 1,54$ & 0.41 \\
Músculo paleta (\%) & $69,22 \pm 2,27$ & $69,98 \pm 2,76$ & 0.45 \\
Gordura paleta (\%) & $6,66 \pm 2,57$ & $6,79 \pm 3,56$ & 0.91 \\
Osso perna (\%) & $24,71 \pm 2,18$ & $23,48 \pm 2,40$ & 0.18 \\
Músculo perna (\%) & $68,37 \pm 3,88$ & $69,80 \pm 2,69$ & 0.28 \\
Gordura perna (\%) & $6,48 \pm 3,05$ & $6,85 \pm 2,52$ & 0.74 \\
& & & \\
\hline & & &
\end{tabular}

CARPENTER, Z.L., KING, G.T., SHELTON, M., et al. Indices for estimating cutability of wether, ram and ewe lamb carcasses. Journal of Animal Science, v. 28, p. 180, 1969. 
COLOMER, F., ESPEJO, M. Influencia del peso al sacrificio y del sexo sobre las características de las canales de cordero de raza Rasa Aragonesa. An. I.N.I.A., Serie Producción Animal, v. 4 , p. $133-50,1973$

EVERITT, G.C., JURY, K.E. Effect of sex and gonadectomy on the growth and development of Southdown $\mathrm{x}$ Romney cross lamb. 2. Effects on carcass grades, measurements and chemical composition. Journal of Agricultural Science, v. 66 , p. $15-27,1966$.

FIELD, R.A. Effect of castration on meat quality and quantity. Journal of Animal Science, v. 32, p. 849, 1971

KEMP, J.D., MAHYUDDIN, M., ELY, D.G., et al. Effect of feeding systems slaughter weight and sex on organoleptics properties, and fatty acid composition of lamb. Journal of Animal Science, v. 51, n. 21, p. 321. 1981

LLOYD, W.R., SLYTER, A.L., COSTELLO. W.J. Effect of breed, sex and final weight on feedlot performance, carcass characteristics and meat palatability of lambs. Journal of Animal Science, v. 51, p. 316-320. 1981.

LOPEZ, M., RODRIGUEZ, M.C., COLOMER, F., et al Producción de carne en la raza Lacha. II. Composición tisular de lechales, ternasco y corderos. Desarrollo de los tejidos. In: XVI JORNADAS CIENTIFICAS DE LA SOCIEDAD ESPAÑOLA DE OVINOTECNIA Y CAPRINOTECNIA Pamplona, España, 1991. Anales... p. 442-450.

MÜLLER, L. Normas para avaliação de carcaças e concursos de carcaças de novilhos. Santa Maria, RS: Universidade Federal de Santa Maria. Departamento de Zootecnia, 1987. 31 p.
OLIVER, W.M., CARPENTER, Z.L., KING, G.T., et al. Qualitative and quantitative characteristics of ram, wether and ewe lamb carcasses. Journal of Animal Science, v. 26, p. 307, 1967.

OSÓRIO, J.C., OSÓRIO, M.T., JARDIM, P.O., et al. Métodos para avaliação da produção de carne ovina: in vivo, na carcaça, na carne. Universidade Federal de Pelotas, Faculdade de Agronomia Eliseu Maciel. Departamento de Zootecnia. Pelotas, RS, Brasil. 39 páginas, 1990.

SAFARI, E., SEFIDBAKHT, N., FARID, A. Effect of castration and cryptorchidism on fatty acid content of ovine adipose tissue. Meat Science, v. 23, n. 1, p. 65-69, 1988.

SAS, Raleigh, NC. SAS User's Guide: Statistics. Cary, NC, 1982. 584 p.

SEIDEMAN, S.C., CROSS, H.R., OLTJEN, R.R., $\boldsymbol{e} \boldsymbol{t} \boldsymbol{a l}$. Utilization of the intact male for red meat production: A review. Journal of Animal Science, v. 55, p. 826. 1982.

SIERRA, I. Producción de cordero joven y pesado en la raza Rasa Aragonesa. I.E.P.G.E., n. 18, 28 p., 1973.

TAYLOR, S.C.S., MURRAY, J.I., THONNEY, M.L. Breed and sex differences among equally mature sheep and goats. 5 . Lipid in dry tissue. Animal Production, v. 49, n. 3, p. 411422, 1989.

THERIEZ, M. Engraissement et qualité des carcasses. Patre, 329, p. $13-15,1985$.

VEZINHET, A., PRUD'HON, M. Evolution of various adipose deposits in growing rabbits and sheep. Animal Production, v. 20, p. 263-370, 1975.

Ciência Rural, v. 29, n. 1, 1999. 